supply worldwide, cloth face coverings can be used as an additional, voluntary public health measure. ${ }^{18}$ Third, once asymptomatic infections have been confirmed, self-quarantine is necessary, and these cases should be required to monitor their health status daily, to contact and follow the advice of their medical provider, and to stay home or wear a mask and remain $2 \mathrm{~m}$ away from other people if they go out. ${ }^{19}$ Because the rate of asymptomatic SARSCoV-2 infection may be high among the close contacts of a symptomatic patients, these contacts should be closely monitored to rule out infection, even if they remain asymptomatic. Finally, scientists and public health experts should conduct research on SARS-CoV-2 to quickly improve the detection capacity and to achieve mass testing of citizens, especially those living in large enclosed facilities and those living and working in high-risk facilities (eg, healthcare workers).

\section{Acknowledgments. None.}

Financial support. This work was supported by the Research Fund of Emergency Project of Prevention and Control for COVID-19 of Central South University of Changsha, China (grant no. 160260003).

Conflicts of interest. All authors report no conflicts of interest related to this work.

\section{References}

1. WHO characterizes COVID-19 as a pandemic. World Health Organization website. https://www.who.int/emergencies/diseases/novel-coronavirus-2019/ events-as-they-happen. Published March 11, 2020. Accessed May 1, 2020.

2. Coronavirus disease 2019 (COVID-19) situation report - 101. World Health Organization website. https://www.who.int/docs/default-source/ coronaviruse/situation-reports/20200430-sitrep-101-covid-19.pdf? sfvrsn=2ba4e093_2. Published April 30, 2020. Accessed May 1, 2020.

3. Wang C, Liu L, Hao X, et al. Evolving epidemiology and impact of non-pharmaceutical interventions on the outbreak of coronavirus disease 2019 in Wuhan, China. medRxiv 2020. doi: 10.1101/2020.03.03.200305 932020.2003.2003.20030593.

4. Gudbjartsson DF, Helgason A, Jonsson $\mathrm{H}$, et al. Early spread of SARS-Cov-2 in the Icelandic population. medRxiv 2020. doi: 10.1101/2020.03.26. 20044446.

5. Mizumoto K, Kagaya K, Zarebski A, Chowell G. Estimating the asymptomatic proportion of coronavirus disease 2019 (COVID-19) cases on board the Diamond Princess cruise ship, Yokohama, Japan, 2020. Euro Surveill 2020;25(10). doi: 10.2807/1560-7917.ES.2020.25.10.2000180.

6. Qiu J. Covert coronavirus infections could be seeding new outbreaks. Nature 2020 Mar 20. doi: 10.1038/d41586-020-00822-x.
7. Asymptomatic COVID-19 cases reach 6,764 on Chinese mainland. The State Council the People's Republic of China website. http://english.www. gov.cn/statecouncil/ministries/202004/15/content_WS5e96c77ac6d0c201c 2cc0fa7.html. Published 2020. Accessed May 1, 2020.

8. Wadman M, Couzin-Frankel J, Kaiser J, et al. How does coronavirus kill? Clinicians trace a ferocious rampage through the body, from brain to toes. Science website. https://www.sciencemag.org/news/2020/04/howdoes-coronavirus-kill-clinicians-trace-ferocious-rampage-through-bodybrain-toes. Published 2020. Accessed May 1, 2020.

9. Sungnak W, Huang N, Bécavin C, et al. SARS-CoV-2 entry factors are highly expressed in nasal epithelial cells together with innate immune genes. Nature Med 2020. doi: 10.1038/s41591-020-0868-6.

10. Chu $\mathrm{H}$, Chan JF, Wang Y, et al. Comparative replication and immune activation profiles of SARS-CoV-2 and SARS-CoV in human lungs: an ex vivo study with implications for the pathogenesis of COVID-19. Clin Infect Dis 2020 Apr 9 [Epub ahead of print]. doi: 10.1093/cid/ciaa410.

11. Zou L, Ruan F, Huang M, et al. SARS-CoV-2 viral load in upper respiratory specimens of infected patients. New Engl J Med 2020;382: 1177-1179.

12. Bai Y, Yao L, Wei T, et al. Presumed asymptomatic carrier transmission of COVID-19. JAMA 2020;323:1406-1407.

13. Kimball A, Hatfield KM, Arons M, et al. Asymptomatic and presymptomatic SARS-CoV-2 infections in residents of a long-term care skilled nursing facility - King County, Washington, March 2020. Morbid Mortal Wkly Rep 2020;69:377-381.

14. Li RA-Ohoo, Pei SA-Ohoo, Chen BA-Ohoo, et al. Substantial undocumented infection facilitates the rapid dissemination of novel coronavirus (SARS-CoV2). Science 2020;368:489-493.

15. He X, Lau EHY, Wu P, et al. Temporal dynamics in viral shedding and transmissibility of COVID-19. Nat Med 2020. doi: 10.1038/s41591-0200869-5.

16. Yin G, Jin H. Comparison of transmissibility of coronavirus between symptomatic and asymptomatic patients: reanalysis of the Ningbo COVID-19 data. medRxiv 2020. doi: 10.1101/2020.04.02.20050740.

17. Arevalo-Rodriguez I, Buitrago-Garcia D, Simancas-Racines D, et al. False-negative results of initial RT-PCR assays for COVID-19: a systematic review. medRxiv 2020. doi: https://doi.org/10.1101/2020.04.16. 20066787.

18. Recommendation regarding the use of cloth face coverings, especially in areas of significant community-based transmission. Centers for Disease Prevention and Control website. https://www.cdc.gov/coronavirus/2019ncov/prevent-getting-sick/cloth-face-cover.html. Updated April 3, 2020. Accessed May 1, 2020.

19. Coronavirus (COVID-19). Centers for Disease Prevention and Control website. https://www.cdc.gov/coronavirus/2019-ncov/index.html. Published 2020. Accessed May 1, 2020.

\title{
Wearing face masks regardless of symptoms is crucial for preventing the spread of COVID-19 in hospitals
}

\author{
Joon Kee Lee MD, $\mathrm{PhD}^{1,3}$ and Hye Won Jeong MD, $\mathrm{PhD}^{2,3}$ (1) \\ ${ }^{1}$ Department of Pediatrics, Chungbuk National University Hospital, Cheongju, South Korea, ${ }^{2}$ Department of Internal Medicine, Chungbuk National \\ University College of Medicine, Cheongju, South Korea and ${ }^{3}$ Department of Infection Control and Prevention, Chungbuk National University Hospital, \\ Cheongju, South Korea
}

\footnotetext{
Author for correspondence: Hye Won Jeong, E-mail: hwjeong@chungbuk.ac.kr Cite this article: Lee JK and Jeong HW. (2021). Wearing face masks regardless of symptoms is crucial for preventing the spread of COVID-19 in hospitals. Infection Control \& Hospital Epidemiology, 42: 115-116, https://doi.org/10.1017/ice.2020.202
}

To the Editor-As of April 16, 2020, the number of confirmed cases of pandemic coronavirus disease 2019 (COVID-19) has reached $1,991,512$, with 130,885 associated deaths. ${ }^{1}$ Although the numbers of confirmed cases and deaths continue to increase steeply through 
person-to-person transmission, asymptomatic or presymptomatic COVID-19 infections mean that mitigating community spread by isolating patients has limitations.,3 Preventing outbreaks in healthcare centers is crucial because the demand for healthcare services is high, and mixing infected persons with those who are immunocompromised and/or elderly is almost unavoidable in these settings. The Centers for Disease Control and Prevention (CDC) of the United States and the Korean Centers for Diseases Control and Prevention (KCDC) have provided guidelines for infection control measures at healthcare facilities. ${ }^{4,5}$ In addition to the use of personal protective equipment by healthcare workers (HCWs), ensuring that all visiting patients and guardians wear face masks and adhere to strict hand hygiene protocols is crucial. Here, we share our experience in preventing the spread of SARS-CoV-2 within a hospital through strict monitoring at the hospital entrance by ensuring that all visitors wear face masks and practice strict hand hygiene.

In South Korea, the first COVID-19 patient was diagnosed on January 20, 2020. Since then, Chungbuk National University Hospital (CBNUH), an 810-bed referral hospital in Cheongju with $\sim 2,300$ employees and 3,000 outpatient visits per day, has undertaken hospital entrance control measures. These measures include reducing the number of unnecessary access points, checking the body temperatures of visitors using a thermal camera, and ensuring that all visitors and employees adhere to hand hygiene protocols and wear face masks, regardless of symptoms. The number of gates to the hospital was reduced from 5 to 2 during the day and to 1 at night.

On March 26, 2020, a point when almost 50\% of COVID-19 cases in South Korea were imported from foreign countries, the regional public health office notified us that a 60 -year-old female COVID-19 patient had visited CBNUH the day before. The KCDC requested an in-hospital epidemiologic investigation of all close contacts because they needed to quarantine them for at least 14 days. We started contact investigations using a photo of the patient and closed-circuit television recordings of the hospital entrance area. We identified the patient trying to enter the hospital. The alarm of the thermal camera was activated because the patient had a fever. To confirm the fever, a contactless thermometer was used by the hospital guard to check her body temperature, which was $38.3^{\circ} \mathrm{C}$. The patient was guided to the COVID-19 screening clinic in a separate area of the emergency department. Nevertheless, the patient tried to re-enter the hospital through another gate. Similarly, the thermal camera was activated, and officials returned her to the COVID-19 screening clinic. The patient and all personnel who encountered her were wearing face masks. We identified 3 persons who had come into close contact with the patient: 2 hospital security guards who were wearing face masks, and 1 hospitalized patient who passed by within 2 meters and was not wearing a face mask. Even though the contact was brief, those who had close contact with this patient self-monitored with delegated supervision for 14 days, ${ }^{6}$ and none became ill with COVID-19.

Although face masks cannot completely prevent COVID-19, patients spread the virus through coughing, ${ }^{7}$ and face masks may reduce the number and travel distance of respiratory droplets. $^{8}$ To prevent hospital spread of COVID-19, hospital entrance control, wearing of face masks, and strict hand hygiene protocols appear to be effective. Wearing eye shields protects HCWs in case of an accidental encounter with patients not wearing face masks. ${ }^{4,5}$ Individual preparedness in accord with major guidelines is crucial in preventing the spread of SARS-CoV-2 in healthcare centers.

Acknowledgments. None.

Financial support. No financial support was provided relevant to this article.

Conflicts of interest. All authors report no conflicts of interest relevant to this article.

\section{References}

1. Coronavirus disease 2019 (COVID-19) situation report - 87. World Health Organization website. https://www.who.int/docs/default-source/coronaviruse/ situation-reports/20200416-sitrep-87-covid-19.pdf?sfvrsn=9523115a_2. Published April 16, 2020. Accessed April 18, 2020.

2. Yu P, Zhu J, Zhang Z, Han Y, Huang L. A familial cluster of infection associated with the 2019 novel coronavirus indicating potential personto-person transmission during the incubation period. J Infect Dis $2020 \mathrm{Feb}$ 18 [Epub ahead of print]. doi: 10.1093/infdis/jiaa077.

3. Bai Y, Yao L, Wei T, et al. Presumed asymptomatic carrier transmission of COVID-19. JAMA 2020 Feb 21 [Epub ahead of print]. doi: 10.1001/jama. 2020.2565 .

4. Interim infection prevention and control recommendations for patients with suspected or confirmed coronavirus disease 2019 (COVID-19) in healthcare settings. Centers for Disease Control and Prevention website. https://www. cdc.gov/coronavirus/2019-ncov/hcp/infection-control-recommendations. html. Updated April 13, 2020. Accessed April 18, 2020.

5. Infection prevention and control recommendations for patients with suspected or confirmed coronavirus disease 2019 (COVID-19) in healthcare settings [in Korean]. Korea Centers for Disease Control and Prevention website. http://ncov.mohw.go.kr/duBoardList.do?brdId=2\&brdGubun=28. Published 2020. Accessed April 18, 2020.

6. Interim US guidance for risk assessment and public health management of healthcare personnel with potential exposure in a healthcare setting to patients with coronavirus disease 2019 (COVID-19). Centers for Disease Control and Prevention website. https://www.cdc.gov/coronavirus/2019ncov/hcp/guidance-risk-assesment-hcp.html Published April 15, 2020. Accessed April 18, 2020.

7. Bae S, Kim MC, Kim JY, et al. Effectiveness of surgical and cotton masks in blocking SARS-CoV-2: a controlled comparison in 4 patients. Ann Intern Med 2020 Apr 6 [Epub ahead of print]. doi: 10.7326/M20-1342.

8. Feng S, Shen C, Xia N, Song W, Fan M, Cowling BJ. Rational use of face masks in the COVID-19 pandemic. Lancet Respir Med 2020 Mar 20 [Epub ahead of print]. doi: 10.1016/S2213-2600(20)30134-X. 